\title{
Influencia de la península de Mejillones en la variabilidad oceanográfica anual e interanual frente al norte de Chile
}

Influence of the Mejillones peninsula in the annual and interannual oceanographic variability off northern Chile

\author{
Jaime Letelier ${ }^{1}$, Luis Soto-Mardones ${ }^{2}$, Sergio Salinas ${ }^{1}$, Leonello Vincenti', \\ Ricardo Pavez ${ }^{3}$ y Marcela Arriagada ${ }^{1}$
}

\author{
${ }^{1}$ Escuela de Ciencias del Mar, Pontificia Universidad Católica de Valparaíso, Av. Altamirano 1480, Valparaíso, Chile. \\ jaime.letelier@gmail.com \\ ${ }^{2}$ Departamento de Física, Facultad de Ciencias, Universidad del Bío-Bío, Avda. Collao 1202, Concepción, Chile \\ ${ }^{3}$ Departamento de Matemática, Facultad de Ciencias, Universidad del Bío-Bío, Avda. Collao 1202, Concepción, Chile
}

\begin{abstract}
The Mejillones Peninsula $\left(23^{\circ} \mathrm{S}\right)$ is a structural zone extending more than $40 \mathrm{~km}$ off the north coast of Chile giving shape to the bays of Mejillones and Moreno which are oriented to the north and south of the peninsula, respectively. The mesoscale oceanographic variability associated with the peninsula was analyzed utilizing satellite information on sea surface temperature, chlorophyll-a concentration, geostrophic currents and Ekman transport. The role of the shape of Mejillones Peninsula in the annual and interannual oceanographic variability of the parameters is revealed by means of Hovmöller diagrams and Empirical Orthogonal Functions. The latitudinal decrease of temperature and chlorophyll is abruptly interrupted by the peninsula. The form and orientation of the Mejillones and Moreno bays favor the retention of upwelled waters and the biological production reflected in the high chlorophyll concentration. This occurs independently of the predominant temperature and Ekman transport in the head and south of the peninsula. The peninsula interrupted and deviates to the west the trajectory of the jet stream, which varies seasonally in intensity and could go more than 100 $\mathrm{km}$ from the coast. In addition, the results show the existence of critical latitude $\left(\sim 22.8^{\circ} \mathrm{S}\right)$ or transition in which there is a marked change in the latitudinal distribution of Ekman transport.
\end{abstract}

Key words: Mejillones, peninsula, surgencia, annual, interannual

\begin{abstract}
Resumen.- La península de Mejillones $\left(23^{\circ} \mathrm{S}\right)$ es un bloque estructural que se proyecta más de $40 \mathrm{~km}$ desde la costa en la zona norte de Chile dando forma a las bahías de Mejillones y Moreno abiertas hacia el norte y el sur, respectivamente. La variabilidad oceanográfica de mesoescala asociada a esta península fue analizada utilizando información satelital de temperatura superficial del mar, concentración de clorofila- $a$, transporte de Ekman y corrientes geostróficas. Mediante el uso de diagrama Hovmöller y Funciones Empíricas Ortogonales estacional e interanual se demuestra el rol que juega la península de Mejillones en la variabilidad de los parámetros oceanográficos en el norte de Chile. El decaimiento latitudinal de la temperatura y clorofila es interrumpido abruptamente por la presencia de la península. La forma y orientación de las bahías de Mejillones y Moreno favorecen la retención de aguas de surgencia y la producción biológica reflejada en altas concentraciones de clorofila observadas, esto ocurre independiente de la temperatura y el transporte predominante en la cabeza y al sur de la península. La península interrumpe y desvía hacia el oeste la trayectoria de la corriente de chorro, la que varía estacionalmente de intensidad y puede alejarse más de $100 \mathrm{~km}$ desde la costa. Además, los resultados muestran la existencia de una latitud crítica $\left(\sim 22,8^{\circ} \mathrm{S}\right)$ o de transición en la que se produce un cambio marcado en la distribución latitudinal del transporte de Ekman.
\end{abstract}

Palabras clave: Mejillones, península, surgencia, anual, interanual

\section{INTRODUCCIÓN}

La península de Mejillones ( $23^{\circ} \mathrm{S}$ ) es un bloque estructural de $60 \mathrm{~km}$ de largo que se proyecta $40 \mathrm{~km}$ hacia el océano desde la costa meridional del norte de Chile (Fig. 1). La península de Mejillones forma un bloque separado de la Cordillera de la Costa, que interrumpe la morfología relativamente lineal del litoral. Esta península alcanza alturas entre 100 m en Punta Angamos (norte) y más de $700 \mathrm{~m}$ en la Punta Tetas (sur) la que puede llegar a desviar hacia el oeste los vientos locales y las corrientes en la zona tal como lo mostró un modelo numérico implementado por Escribano et al. (2004). Esta zona forma parte del sistema de corrientes de Perú-Chile por lo que los patrones regionales de circulación oceánica y meteorológica son conducidos por el Anticiclón Subtropical del Pacífico Sur (APS) (Strub et al. 1998). La orientación de la costa en el norte de Chile permite que la 


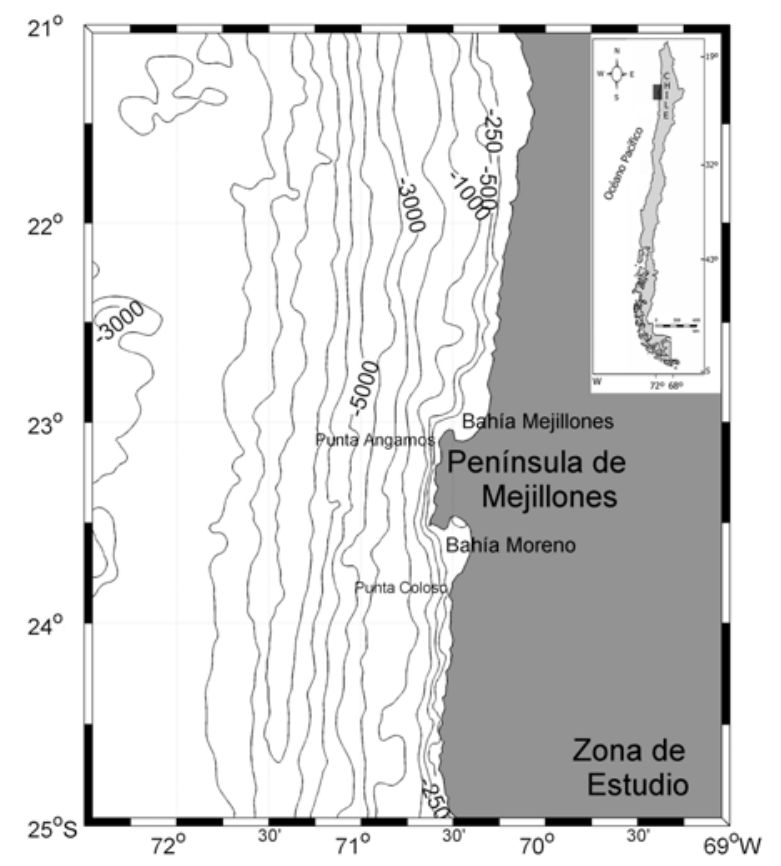

Figura 1. Mapa de la península de Mejillones / Map of the Mejillones peninsula

componente del viento hacia el Ecuador predomine durante casi todo el año, por lo que se producen periódicamente procesos de surgencia costera cuyos principales focos están asociados a penínsulas, puntas y bahías (Fonseca \& Farías 1987, Hormazábal et al. 2001, Rutllant et al. 2003). Esta península está ubicada entre los extensos centros de surgencia de Perú $\left(14^{\circ} \mathrm{S}\right)$ y de Chile Central $\left(36^{\circ} \mathrm{S}\right)$. En esta área interactúan aguas de origen subtropical y ecuatorial subsuperficial con aguas de origen subantártica e intermedia antártica (Sievers \& Silva 1982, Silva 1983). Además, de 3 a 7 años se manifiestan los efectos de eventos ecuatoriales El Niño y La Niña, los que modifican la proporción de las masas de agua presentes (Reyes 2004), la surgencia en la costa (Hormazábal et al. 2001), el nivel del mar (Pizarro et al. 1994), las corrientes a lo largo de la costa (Shaffer et al. 1997), el viento y la temperatura en la columna de agua (Blanco et al. 2002).

La singular forma de esta península da origen a dos bahías: la bahía Mejillones mirando hacia el norte y bahía Moreno abierta hacia el sur (Rojas \& Silva 1996). Estos rasgos topográficos locales en conjunto con la circulación oceánica y atmosférica regional permiten la formación de

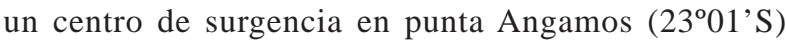
ubicado en la punta norte de la península (Fonseca \& Farías 1987, Marin et al. 1993), aunque también generan que toda el área este bajo la influencia directa de otro

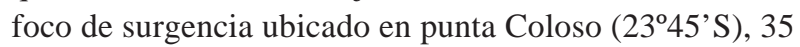
$\mathrm{km}$ al sur de bahía Moreno. La interacción entre la surgencia producida en estos focos y la península produce procesos de 'sombras de surgencia', es decir, ambas bahías sufren el efecto indirecto de las lenguas de surgencia que se proyectan hacia el noroeste de la península (Escribano \& Hidalgo 2001, Marin et al. 2003, Thiel et al. 2007).

Además, y adyacente a la península se desarrollan remolinos de mesoescala y filamentos ciclónicos y/o anticiclónicos que transportan las aguas surgidas hacia la zona de transición costera (ZTC) dejando una marca superficial en el campo de temperatura y clorofila. Este tipo de procesos y estructuras oceanográficas han sido observadas en información satelital y en datos hidrográficos de crucero (Reyes et al. 2007, 2009).

Los antecedentes y la escala espacial de península permiten establecer como objetivo de este trabajo determinar el efecto que ejerce la presencia de la península de Mejillones en la circulación oceánica y atmosférica de mesoescala local, forzada por la variabilidad anual e interanual de la circulación regional. Este trabajo utiliza como proxy la evolución temporal y espacial de los campos superficiales de temperatura, clorofila, viento y corrientes derivados de información satelital.

\section{Materiales y Métodos}

Para describir y cuantificar los patrones superficiales se utilizaron imágenes satelitales con los promedios mensuales de temperatura superficial del mar, TSM $\left({ }^{\circ} \mathrm{C}\right)$ y clorofila- $a$, Cloa ( $\mathrm{mg} \mathrm{m}^{-3}$ ) con una resolución espacial de $4 \times 4 \mathrm{~km}$ las que abarcaron entre julio de 1992 a diciembre de 2010. Las imágenes provinieron del sensor MODIS (Moderate Resolution Imaging Spectroradiometer) ubicado a bordo del satélite de Aqua y que son distribuidas por el programa OceanColorWeb ${ }^{1}$.

Paralelamente, se utilizaron promedios mensuales del esfuerzo del viento $\left(\mathrm{N} \mathrm{m}^{-2}\right)$ de 12,5 $\mathrm{km}$ de resolución espacial derivadas de bases de datos 'along track' (a lo largo del track) diarias de viento satelital del escaterómetro QuikScat. A partir de las bases along track se construyeron imágenes grilladas del Pacifico Sur oriental. Esta información grillada es la que permite aplicar estadísticas avanzadas como Funciones Empíricas Ortogonales. Estos promedios mensuales abarcan el

${ }^{1}<$ http://oceancolor.gsfc.nasa.gov> 
periodo entre julio de 2002 a octubre de 2009, fecha en la que el satélite fue dado de baja. La información proviene del programa de distribución de datos PO.DAAC 'Physical Oceanography Distributed Active Archive Center', perteneciente al Jet Propulsion Laboratory del Instituto de Tecnología de California ${ }^{2}$. El esfuerzo del viento a lo largo de la costa $\left(T_{\mathrm{y}}\right)$ permitió calcular el transporte perpendicular a la costa $\left(\mathrm{Mx}=T_{\mathrm{y}} f^{-1}\right.$, donde $f$ es el parámetro de Coriolis) (Pond \& Picard 1983).

Además, se utilizaron datos globales georeferenciados de velocidades geostróficas derivadas de imágenes satelitales de altimetría diaria y semanal de $0,33^{\circ}$ de resolución espacial, las que abarcan entre julio de 2002 a diciembre de 2010. Los datos de altimetría fueron obtenidos del programa Archiving, Validation and Interpretation of Satellite Oceanographic data $\left(\mathrm{AVISO}^{3}\right)$ y corresponden a un producto que combina las observaciones de los satelitales Topex Poseidon, Jason1, ERS-1, ERS-2 y Envisat.

Las imágenes globales de TSM, Cloa, nivel del mar y velocidades geostróficas fueron reducidas desde una escala global al área comprendida entre los $21^{\circ}$ y $25^{\circ} \mathrm{S}$ y entre la costa $\left(70^{\circ} \mathrm{W}\right)$ y los $73^{\circ} \mathrm{W}$. La escala espacial considerada tiene como fin reducir el error generado cerca de la costa al considerar la continuidad espacial de la información asociada a la estrechez de la plataforma continental. En particular, la TSM promedio mensual se obtuvo promediando imágenes diarias de las pasadas ascendentes y descendentes del satélite. Valores puntuales mayores a 2 desviaciones estándar respecto de las climatologías del Atlas Hidrográfico de la Armada fueron eliminados (Rojas \& Silva 1996). Se obtuvieron imágenes mensuales de Cloa promediando de igual forma, mientras que los promedios mensuales de viento y velocidades geostróficas se construyeron promediando respectivamente las componentes zonales y meridionales.

Utilizando los promedios mensuales se construyeron climatologías (no mostradas), y se utilizaron diagramas latitud vs tiempo (diagramas Hovmöller) para representar la variabilidad temporal y espacial de las diferentes variables en una banda que abarcó desde la costa y los $50 \mathrm{~km}$ mar afuera. También se incorporaron diagramas meridionales promedio con su respectiva desviación estándar y un diagrama que muestra la diferencia entre la zona costera y la zona oceánica que muestran la influencia de la península en la distribución espacial de los

\footnotetext{
${ }^{2}<$ http://podaac.jpl.nasa.gov>

${ }^{3}<$ http://www.aviso.oceanobs.com>
}

parámetros. Para determinar si existe influencia de la península en la distribución espacial de TSM se analizó la zona de la península en relación de las zonas adyacentes utilizando el método estadístico Modelo Dato Panel desarrollado por Grunfield (1958) e implementado por Croissant \& Millo (2008).

Además, se incluyó un análisis de Funciones Empíricas Ortogonales (FEOs) a las variables para cuantificar la variabilidad del sistema representada en modos ortogonales o independientes entre sí que muestran los diferentes procesos que afectan a la zona (Barnett 1981, Venegas 2001).

Las FEOs permiten cuantificar la varianza total de las series de temperatura, clorofila, corrientes, viento y TSM, para obtener modos o estructuras espaciales (modo espacial) que contienen el mayor porcentaje de la varianza de la variable la que además fluctúa temporalmente (modo temporal) y que muy probablemente representan a las señales de los procesos geofísicos dominantes en la región de estudio (Barnett \& Patzert 1980, Kelly 1985). La ventaja de trabajar con información satelital es que todos los procesos oceanográficos y meteorológicos superficiales tienen un alto grado de coherencia espacial que permite reconocerlos en los patrones de variabilidad espacial presentados en los modos espaciales de la FEOs (Bjornsson \& Venegas 1997).

En términos prácticos, los análisis de los FEOs se aplicaron a las series mensuales sin tendencia, con y sin señal anual de tal manera de analizar la influencia de los cambios estacionales y los fenómenos interanuales, respectivamente. Para obtener las anomalías de los diferentes parámetros se sustrajo aritméticamente la señal anual calculada de las series mensuales originales. Finalmente, las series fueron normalizadas para compararlas. Las gráficas del modo temporal de las FEOs de las variables analizadas incluyeron el periodo 20022010, aunque el viento solamente hasta 2009, debido a que ese año QuickScat dejó de funcionar. Las series resultantes de las FEOs que muestran la evolución temporal de la estructura espacial fueron comparadas con el índice de El Niño reportado por el Centro de Predicción del Clima de la NOAA.

\section{Resultados}

\section{TEMPERATURA SUPERFICIAL DEL MAR}

La distribución espacial de la TSM en la banda costera (Fig. 2a), mostró un marcado comportamiento estacional con las máximas temperatura en verano $\left(\sim 21,5^{\circ} \mathrm{C}\right)$ y 
mínimas en invierno $\left(\sim 16^{\circ} \mathrm{C}\right)$. Además, la TSM evidenció un suave decaimiento latitudinal que se mantiene a lo largo de todo el año, como lo confirmó el promedio temporal en función de la latitud de la TSM (Fig. 2b). Este promedio también muestra que la variabilidad anual de la TSM (desviación estándar) tiene la misma amplitud a lo largo del meridiano. El decaimiento latitudinal es interrumpido en los extremos de la cabeza de la península de Mejillones (punta Tetas y punta Angamos), donde la TSM disminuye abruptamente $0,5^{\circ} \mathrm{C}$ (Fig. 2c). Esta disminución ocurre entre los periodos de primavera y otoño asociados a los dos focos de surgencia reconocidos en la zona. El promedio estacional con su desviación estándar entre la región norte (entre $17^{\circ} \mathrm{C}$ y $21^{\circ} \mathrm{C}$ ) y el sur (entre $16^{\circ} \mathrm{C}$ y $20^{\circ} \mathrm{C}$ ) muestra una diferencia constante de aproximadamente $1^{\circ} \mathrm{C}$. La perturbación generada en el decaimiento de la TSM producto de la presencia de la península no alcanzó los $200 \mathrm{~km}$ fuera de la costa (Fig. 2c), es decir, está restringido espacialmente a los primeros $50 \mathrm{~km}$. El resultado del Modelo Dato Panel (Grunfield 1958), detectó como significativas (95\%) las diferencias entre la TSM observada y la TSM de las zonas adyacentes.

El resultado de las FEOs aplicadas a la secuencia mensual de imágenes (2002-2010) de TSM evidenció, en el primer modo de variación espacial, la presencia de una señal estacional dominante que explica la mayor parte de la variabilidad de la TSM (64\%) (Fig. 2f, línea roja). La estructura espacial de este modo (Fig. 2d) mostró en la región norte las máximas amplitudes en forma de una lengua con un suave decaimiento hacia el sur. Esta distribución se intensificó entre diciembre y enero de cada año. El segundo modo que contribuye con el $11 \%$ de la varianza total también mostró una estructura temporal dominada por una señal estacional, aunque desfasada un mes del pico del primer modo (Fig. 2f, en contorno azul). La estructura espacial de este segundo modo (Fig. 2e) indica que las mayores amplitudes se encuentran en la región oceánica decayendo hacia la costa, pero más rápidamente frente a la península. Esta distribución espacial se intensificó durante el desarrollo del verano austral, periodo de aumento de la surgencia y del contraste térmico costa-océano. El decaimiento abrupto hacia la costa coincidió con la presencia de intensos gradientes térmicos asociados a frentes de surgencias $\left(0,01\right.$ a $\left.0,03^{\circ} \mathrm{C} \mathrm{km}^{-1}\right)$. En resumen, las FEOs de la TSM muestran en ambos modos la influencia de la escala anual pero que se diferencian por que el primero describe un calentamiento-enfriamiento casi uniforme norte a sur y el segundo muestra una oscilación costa-océano. La distribución espacial del modo 1 de la señal original y de la anomalías (Fig. 2d,g) muestran un punto de quiebre entre la zona norte y sur de la península, limitado por contornos cerrados de 0,9 y 0,6, respectivamente. Mientras que el modo 2 (Fig. 2e,h) muestra una oscilación costa-océano, vinculada a la formación de la banda costera de aguas frías forzada por la surgencia costera.

El análisis de las FEOs aplicado a las series mensuales de las anomalías de TSM (Fig. 2g-i) revelaron que las estructuras espaciales y temporales de los dos primeros modos explican el $26 \%$ y el $11 \%$ de la varianza total, respectivamente. La estructura temporal (Fig. 2i, contorno rojo) que indica la variabilidad del patrón espacial de la TSM (Fig. 2g) se mostró en fase positiva entre 2002 y 2004, mientras que para este mismo periodo el modo 2 se encontró en fase negativa. Lo anterior muestra que se incrementó el gradiente meridional y se invirtió en gradiente zonal al volverse más cálido hacia el norte y en la banda costera durante el periodo de El Niño 2002-2003. El resto del periodo no mostró coherencia con los eventos cálidos o fríos.

\section{Clorofila}

La distribución de la concentración de clorofila a lo largo de la costa (Fig. 3a) define la presencia de 3 zonas características: la región norte $\left(21^{\circ} \mathrm{S}\right.$ hasta $\left.\sim 22,3^{\circ} \mathrm{S}\right)$, la región sur $\left(\sim 23,8^{\circ} \mathrm{S}\right.$ hasta $\left.25^{\circ} \mathrm{S}\right)$ que incluye la cabeza de la península de Mejillones y por último las áreas de las bahías Mejillones y Moreno.

La zona de las bahías se caracteriza por poseer las mayores concentraciones respecto a toda la zona durante todo el año y donde los máximos aparecen entre finales de invierno y principios de primavera. Ambas bahías alcanzan las mayores concentraciones en agosto, los resultados también muestran que la bahía Mejillones en promedio puede sobrepasar los $9 \mathrm{mg} \mathrm{m}^{-3}$ mientras que en bahía Moreno solamente puede alcanzar un máximo promedio de $7 \mathrm{mg} \mathrm{m}^{-3}$.

Al norte de la península $\left(21^{\circ} \mathrm{S}\right.$ hasta $\left.22,3^{\circ} \mathrm{S}\right)$, las concentraciones oscilaron entre $2 \mathrm{mg} \mathrm{m}^{-3}$ en verano y un máximo a principios de primavera $\left(\sim 7,5 \mathrm{mg} \mathrm{m}^{-3}\right)$. Finalmente, en la región sur se observaron las concentraciones mínimas de clorofila $\left(<2 \mathrm{mg} \mathrm{m}^{-3}\right)$ durante todo el año con un leve incremento a finales del invierno austral. 

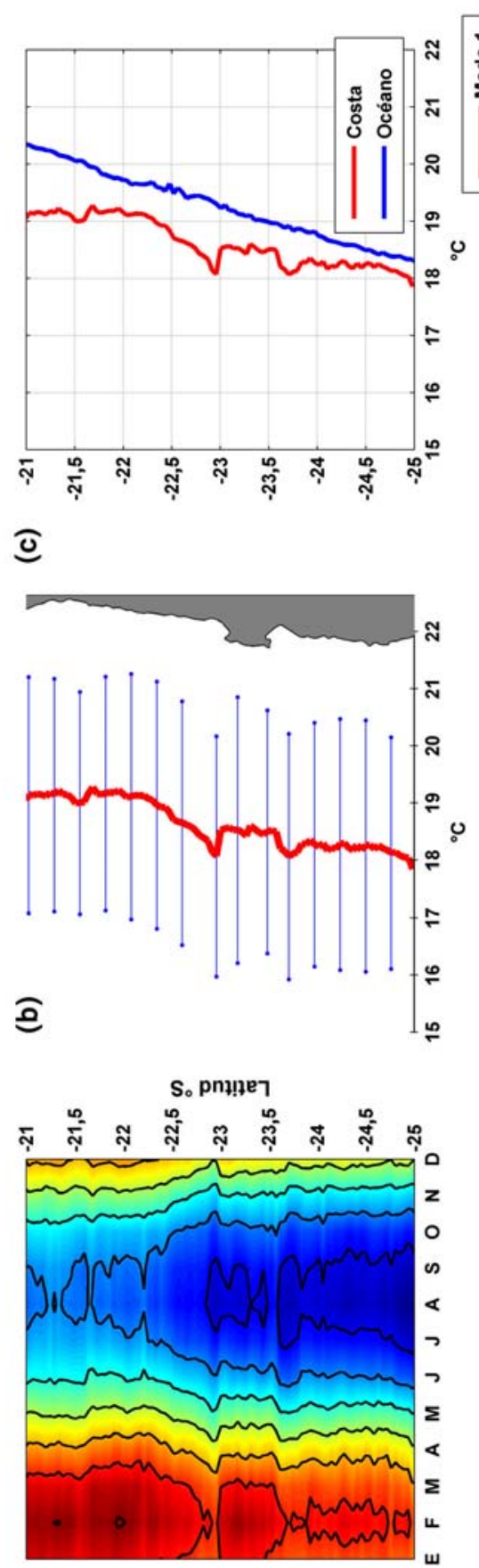

(ี)

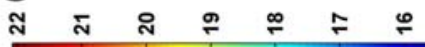

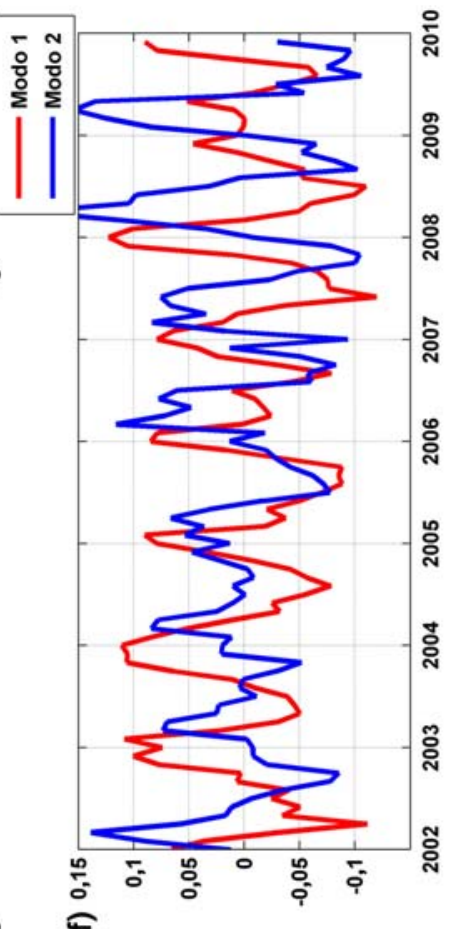

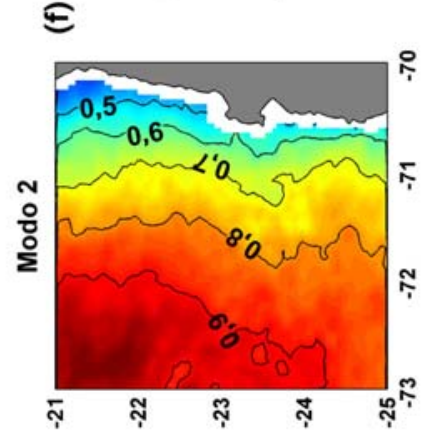

@

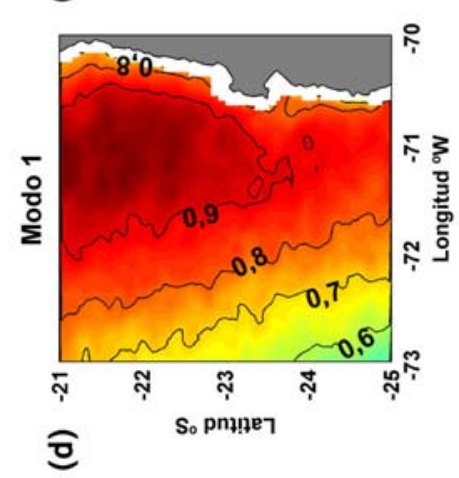

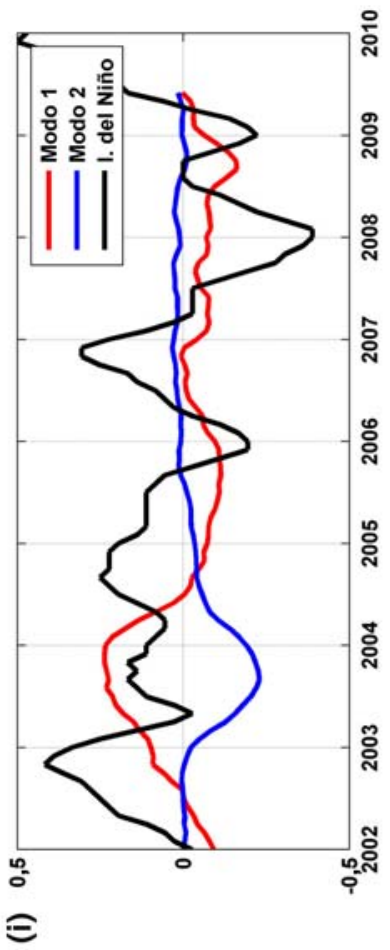

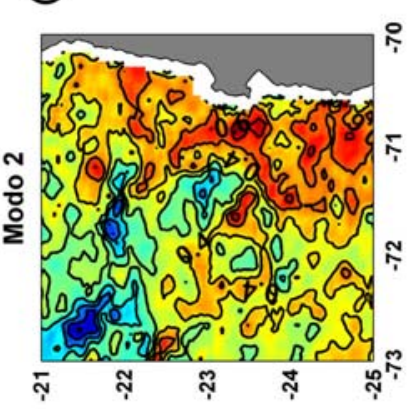

ఏิ

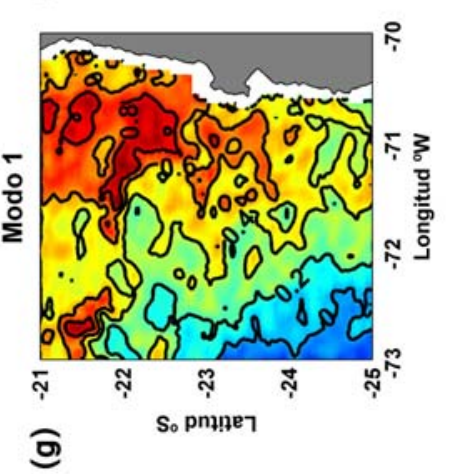

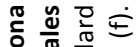

N

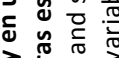

तั

ฟิ

उٓ फे

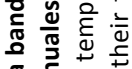

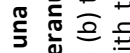

ฮ . हो

준 离

을 它

ษ 훠

을 응 웡

날

흐ㅇㅝㅛ

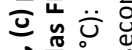

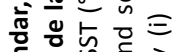

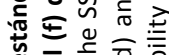

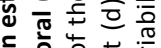

흐 흔

苛

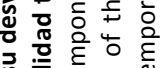

जิ

高

ह

$\Phi 心$

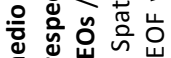

ठ 는

흥 웡호

๘)

흥응 힌

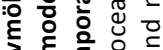

우 응 ह 덩

로 융 응

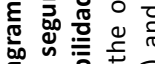

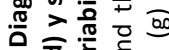

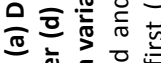

তิ่

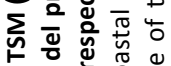

즈 잉

응 는 은

는 은

ชั

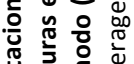

पै

竎 융 중

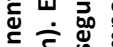

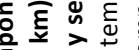

응 总可

نั

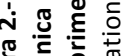

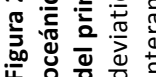


El promedio temporal de la concentración de clorofila en función de la latitud (Fig. 3b) y su variabilidad estacional confirman claramente la presencia de estas 3 zonas, donde la cabeza de la península de Mejillones actúa como una barrera latitudinal identificada con una concentración mínima ( $\pm 1 \mathrm{mg} \mathrm{m}^{-3}$ ). Por otro lado, las bahías parecen actuar como focos de alta concentración de clorofila estacionalmente sincronizadas e independientes de la zona (Fig. 3c). Cabe señalar que la clorofila en ambas bahías presentó un comportamiento semianual, ya que alcanzan dos máximos. En Mejillones el mayor pico se observó en agosto $\left(9 \mathrm{mg} \mathrm{m}^{-3}\right)$ y uno menor en marzo (6,5 $\mathrm{mg} \mathrm{m}^{-3}$ ), mientras que en bahía Moreno el máximo pico coincidió con Mejillones en agosto (5,5 $\mathrm{mg} \mathrm{m}^{-3}$ ), pero el menor se observó en mayo. La figura 3c muestra claramente las diferencia entre la banda costera y el océano. En la banda costera se observa una alta variabilidad y un decaimiento latitudinal asociado a las 3 zonas interrumpido por dos máximos $\left(\sim 6 \mathrm{mg} \mathrm{m}^{-3}\right)$ en la bahías y un mínimo en la cabeza de la península ( $1 \mathrm{mg}$ $\mathrm{m}^{-3}$ ), mientras que en la zona oceánica mostró bajos de niveles de clorofila $\left(<1 \mathrm{mg} \mathrm{m}^{-3}\right)$ sin una variabilidad significativa a lo largo de las latitudes.

El análisis de FEOs realizado a la concentración de clorofila mensual mostró que los dos primeros modos explicaron un $71 \%$ de la variabilidad espacio-temporal (Fig. $3 d$,e). El primer modo explica el $62 \%$ de la varianza, donde la estructura espacial (Fig. 3d) muestra la formación de banda costera de mayores concentraciones en la región norte, limitadas al oeste por un decaimiento exponencial y limitadas al sur por la presencia de la península. La evolución temporal (Fig. 3f, contorno rojo) del modo 1 no presentó una señal anual o estacional clara aunque se intensifica levemente entre invierno y primavera. Cabe mencionar un aumento anómalo de concentración a principios del invierno del 2003, primavera 2005 y el otoño 2008 los que se deben posiblemente a eventos de origen remoto, como El Niño o La Niña.

El segundo modo que contribuye con el 9\% de la varianza explicada (Fig. 3e) presentó una oscilación entre la región norte y la zona de las bahías; esta oscilación está centrada en la latitud $\sim 23,8^{\circ} \mathrm{S}$, la cual coincide a las encontradas en el primer y segundo modo de la TSM (Fig. 2d,e). Además, se observó un incremento de la clorofila en la zona oceánica del sector norte coincidiendo con lo descrito para la costa de Chile central por Yuras et al. (2005) y Correa-Ramírez et al. (2007). La variabilidad temporal (Fig. 2f, contorno azul) muestra coincidencia con los aumentos anómalos observados en la evolución temporal del primer modo (Fig. 2f, contorno rojo), aunque también es posible observar como en el 2003, 2004 y 2008 ambos modos se encuentran en fase opuesta.

Las estructuras espaciales (Fig. 3g, h) y temporales (Fig. 3i) de los dos primeros modos de las anomalías de la concentración de clorofila explicaron más de 52\% de la varianza total. La variabilidad temporal de ambos modos (Fig. 3i, contornos rojo y azul) muestran fluctuaciones de largo periodo ( 3 años) más que asociaciones con el índice de El Niño (contorno negro), una fase positiva entre 2003 y comienzos de 2005, como también una fase negativa entre 2005 y 2007. Las estructuras espaciales (Fig. 2g, h) muestran una banda a lo largo de la costa entre los $21^{\circ} \mathrm{S}$ y la bahía de Mejillones, limitada al sur por la presencia de la península ya que al sur la banda costera desaparece.

\section{Transporte de EkMAN}

La distribución temporal del transporte de Ekman en función de la latitud (Fig. 4a-c), mostró un comportamiento diferenciado espacialmente entre el norte y sur de la península. Al norte de $22^{\circ} \mathrm{S}$ predominaron intensidades mayores a $5 \times 10^{3} \mathrm{~m}^{3} \mathrm{~s}^{-1}$ entre agosto y diciembre, mientras que al sur de los $22^{\circ} \mathrm{S}$ los máximos (>6 $\left.\times 10^{3} \mathrm{~m}^{3} \mathrm{~s}^{-1}\right)$ se observaron a lo largo de toda la costa entre agosto y octubre, mientras que durante febrero se observó un máximo al norte y otro al sur de la península (Fig. 4a). La variabilidad espacial del transporte se observa más claramente en el promedio del transporte (Fig. 4b) y su respectiva desviación estándar en la cual aparece un quiebre $\left(\sim 22,8^{\circ} \mathrm{S}\right)$ en la tendencia latitudinal. Al comparar la zona costera con la oceánica (Fig. 4c) se aprecia que las intensidades son menores en la costa pero con mayor variabilidad. A pesar de lo anterior, en ambas zonas se aprecia un incremento latitudinal con un quiebre en $22,8^{\circ} \mathrm{S}$ revelando un proceso de mayor escala. Al mismo tiempo la distribución costera mostró que en la ubicación de la península se produce un proceso local que genera dos quiebres en la tendencia latitudinal del transporte. La presencia topográfica irregular de la península generó un quiebre abrupto entre el norte y sur, con un máximo en Mejillones $\left(6 \times 10^{3} \mathrm{~m}^{3} \mathrm{~s}^{-1}\right)$ y un mínimo en Moreno (5,5 x $10^{3} \mathrm{~m}^{3} \mathrm{~s}^{-1}$ ) después del cual vuelve a aumentar. Este gradiente latitudinal local $\left(22,8\right.$ a $\left.23,8^{\circ} \mathrm{S}\right)$ en el transporte (Fig. 4c), genera un rotor positivo favoreciendo los flujos anticiclónicos y una divergencia hacia el oeste que fortalece la surgencia generada en la península. De la misma manera hacia el norte de $22,8^{\circ} \mathrm{S}$ se genera un rotor negativo favoreciendo la convergencia hacia la costa y a los flujos hacia el norte, lo que es consistente con la entrada de la corriente de chorro. 

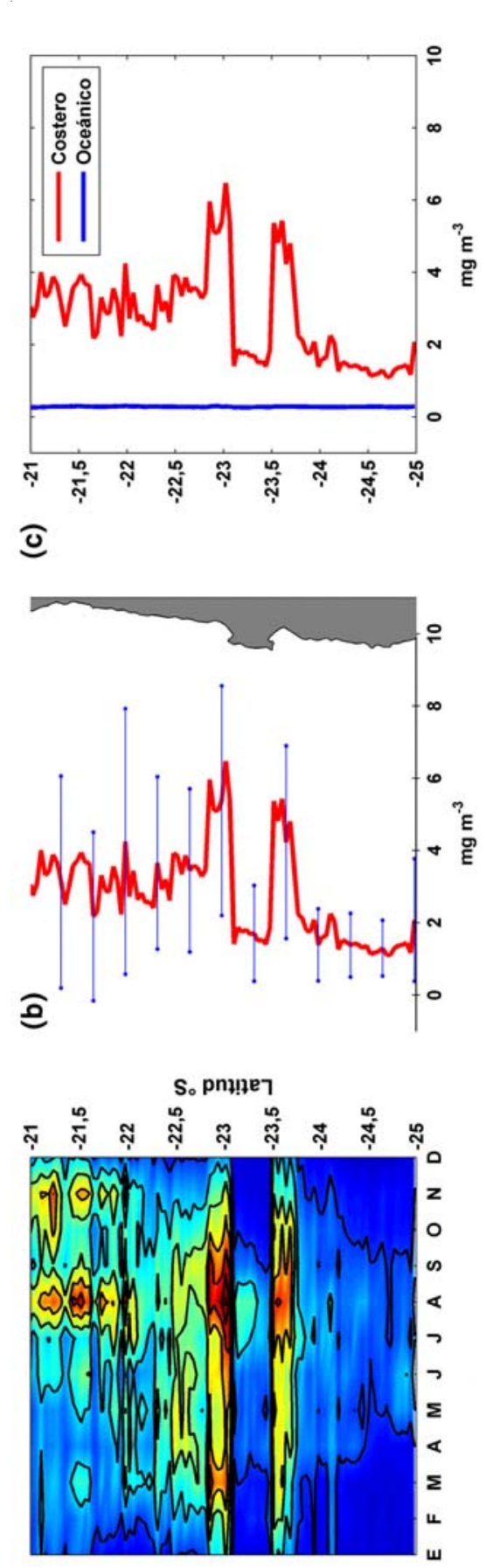

ฮ

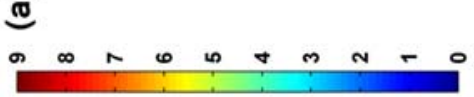

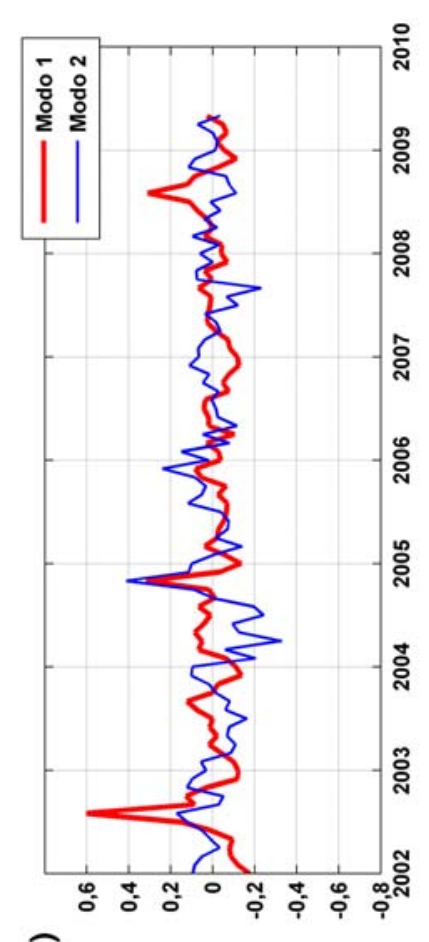

ะั
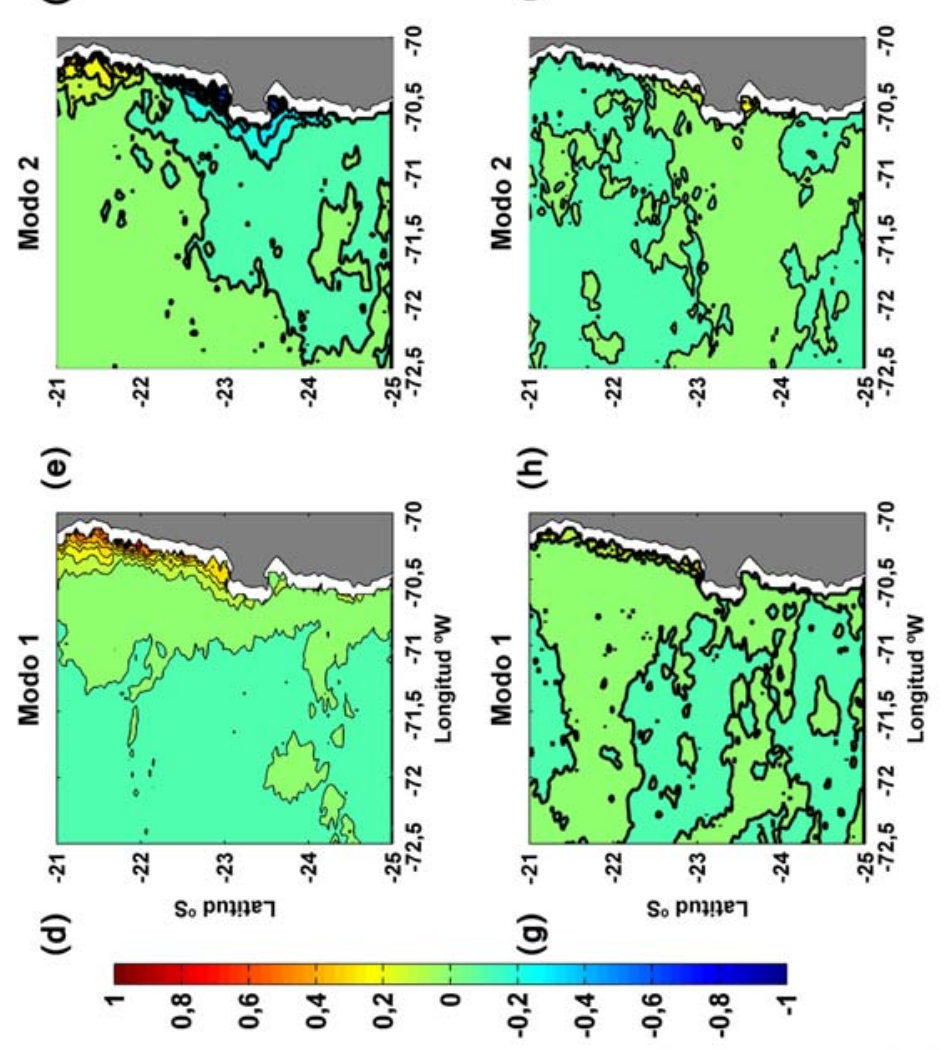

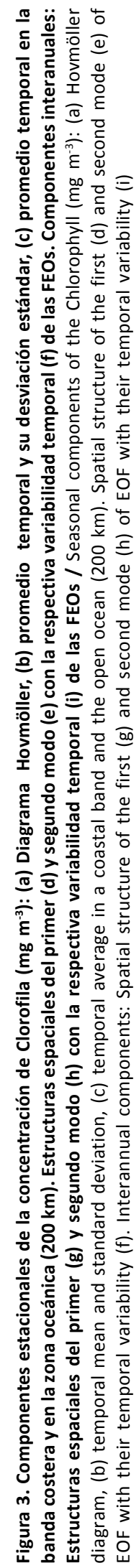


La distribución del transporte de Ekman es imprescindible para explicar la evolución temporal y espacial de la banda costera de aguas frías observada en la TSM (Fig. 2a) y la respuesta inversa de la distribución de clorofila (Fig. 3a). Los resultados muestran que entre abril a noviembre, desde la latitud crítica hacia el sur el transporte va aumentando mientras que la clorofila disminuye (Fig. 3c). En cambio en los meses de verano ocurre la situación inversa. De este comportamiento queda excluida la zona asociada a las bahías Mejillones y Moreno por la retención que produce su singular línea de costa (Fig. 3a).

El resultado del análisis de las FEOs realizado al transporte de Ekman mostró que los primeros dos modos concentraron el $75 \%$ de la varianza total. De este porcentaje, el primer modo explicó el 55\%, mostrando que las mayores amplitudes se encontraron en la región sur y decaen hacia el ‘codo’ de Arica (Fig. 4d). La variabilidad temporal (Fig. 4f, contorno rojo) muestra un comportamiento estacional, con transporte máximo en verano y mínimo en invierno (Fig. 4a). El comportamiento del modo 1 reveló una inversión de la distribución espacial a principio de todos los inviernos que se intensificó los años 2000, 2005 y 2008 mientras que la distribución espacial del modo 1 se vio fortalecida en los periodos de primavera principalmente entre el 2002 y 2004. Estas distribuciones coinciden con el ciclo estacional observado en el modo 1 de la TSM (Fig. 2f, contorno rojo) y las fase inversa del modos 1 y 2 de las anomalías de TSM durante 2002-2004 (Fig. 2i) y un incremento anómalo de la concentración de clorofila (Fig. 3i).

Al calcular la correlación cruzada entre las series temporales del primer modo de la TSM, el transporte de Ekman y la clorofila se encontraron coeficientes del orden de $r \approx-0,3$ y $r=-0,4$, respectivamente. A pesar del valor del índice de correlación entre transporte de Ekman y la Clorofila $(r=-0,4)$, ésta indica un grado de dependencia físico inverso entre ambas variables, donde obviamente el transporte es el forzante.

Los FEOs resultantes de la anomalía del transporte de los dos primeros modos explican el $39 \%$ y el $22 \%$ de la varianza total, respectivamente (Fig. 4g, h). La estructura temporal (Fig. 4i) que modula el patrón espacial del modo 1 (Fig. 4g) se encuentra en fase opuesta con la del modo 2 durante el periodo de 2001-2004 y no parecen coherentes con el índice El Niño (Fig. 4i, contorno negro).

\section{CoRriente}

Dentro de los patrones de circulación en la zona se destaca la corriente de chorro (Jet) a lo largo de la costa (Aguirre et al. 2011). El diagrama de Hovmöller que muestra la climatología de corriente (Fig. 5a) muestra un flujo costero preferencialmente hacia el ecuador, el que es más intenso en la región al sur de la península (Fig. 5b). En latitudes medias y en presencia de la península, la corriente de chorro se desvía abruptamente frente a punta Tetas. Esta desviación hacia el oeste es más intensa entre noviembre y abril debilitándose en invierno. Al norte de la latitud crítica $\left(\sim 22,8^{\circ} \mathrm{S}\right)$ y donde el rotor favorece el flujo hacia la costa, el chorro costero tiende a converger hacia el este en el límite de los $21,4^{\circ} \mathrm{S}$ y continuar hacia el norte. La figura $5 \mathrm{c}$ muestra el aumento del flujo hacia el oeste en presencia de la península y el retorno al norte de la península con magnitudes mayores a $13 \mathrm{~cm} \mathrm{~s}^{-1}$ al norte de la península, situación que no se observa en el sector oceánico, lo que revela el impacto que genera la presencia de esta estructura.

El análisis de FEOs sobre los campo de corrientes mostró que los dos primeros modos explican el 25\% (modo 1) y $12 \%$ (modo 2) de la varianza total. La estructura espacial del primer modo (Fig. 5d) permite visualizar una oscilación costa-océano, donde las máximas amplitudes se observaron en la región sur decayendo hacia el norte. Un similar comportamiento se observó en la estructura espacial del modo 2 con una oscilación norte-sur (Fig. 5e). La evolución temporal de la señal original (Fig. 5f) es oscilante con máximos y mínimos durante el año, no evidenciando una señal anual clara. Las oscilaciones observadas en el modo temporal de las corrientes (Fig. 5f) tiene una periodicidad de 60 a 90 días, las cuales coinciden con la frecuencia de ondas atrapadas a la costa (Hormazábal et al. 2001, Pizarro et al. 2002). Esta afirmación está siendo analizada, ya que requiere un análisis paralelo de las fluctuaciones de nivel del mar en la costa de Antofagasta para concluir tal hipótesis.

Las FEOs de las anomalías resultantes mostraron que los dos primeros modos explicaron el $15 \%$ y el $12 \%$, respectivamente. Ambas estructuras espaciales (Fig. 5g,h) muestran una oscilación norte-sur modulada por una evolución temporal del primer modo (Fig. 5i) la que presentó amplitudes positivas durante período 2002-2005 y mostrando coherencia con el evento La Niña 2006. La evolución temporal del segundo modo (Fig. 5i, contorno azul) apareció asociado con el evento cálido más intenso de la serie, El Niño 2002-2003, en cambio durante los otros eventos se observaron en fase opuesta. 

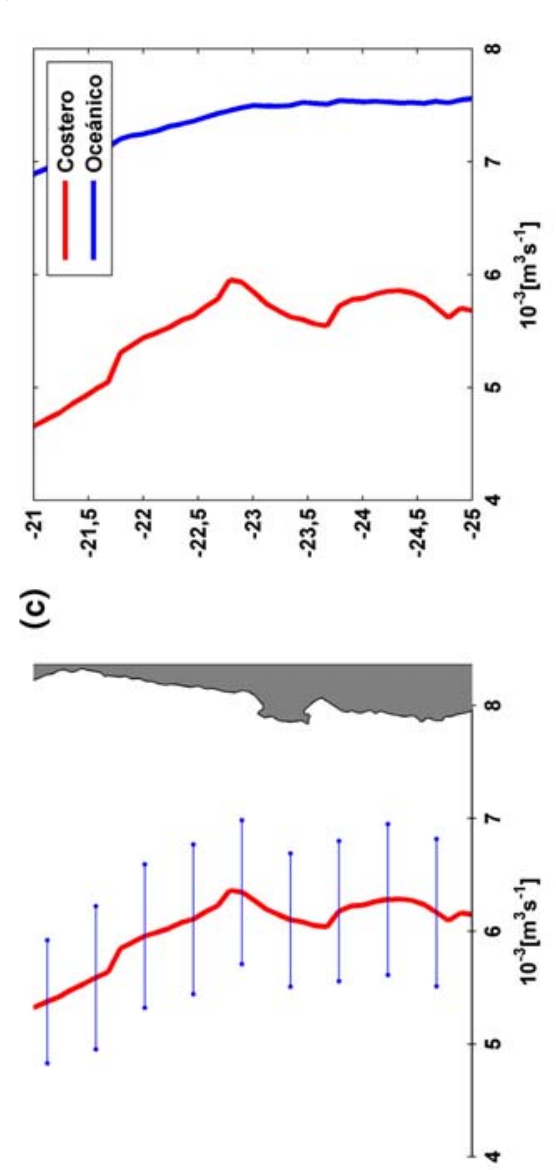

อ

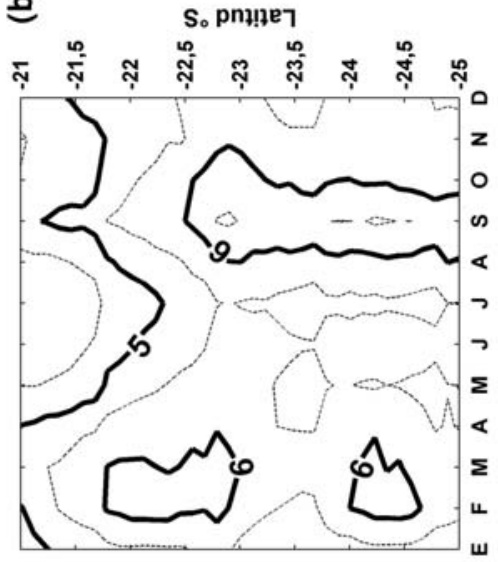

ฮิ

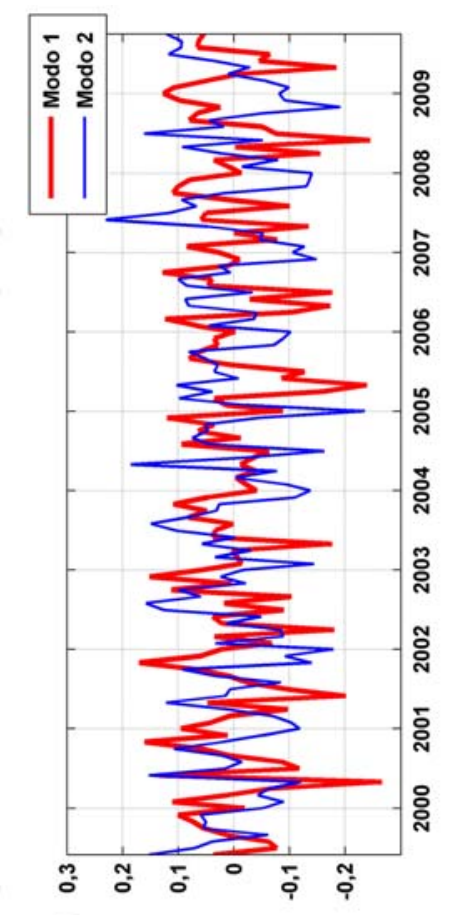

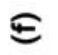

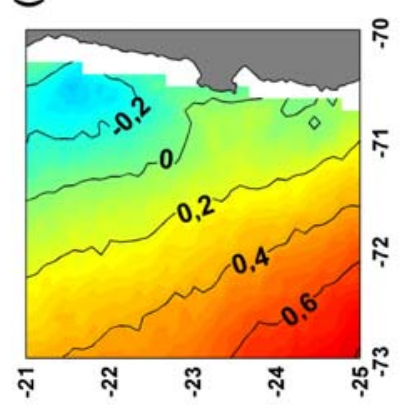

๑)

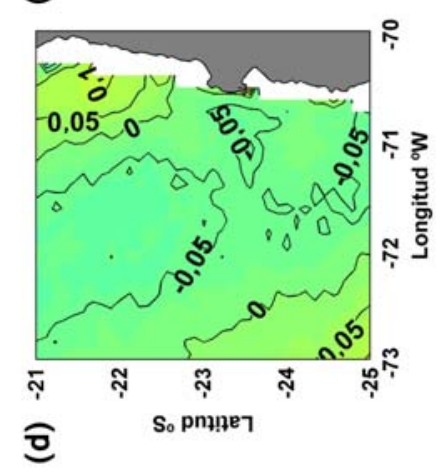

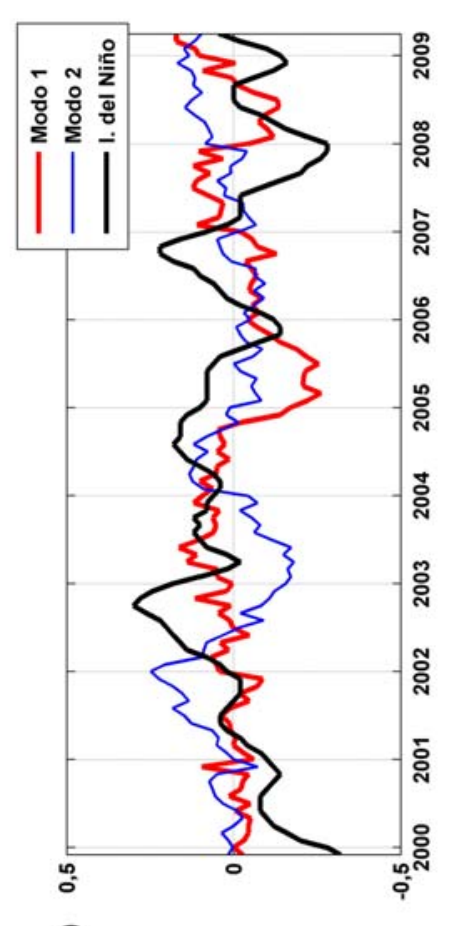

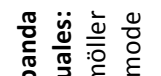

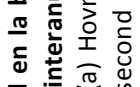

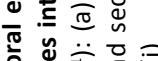

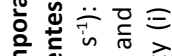

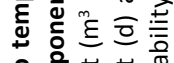

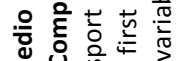

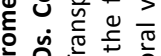

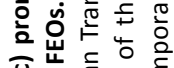

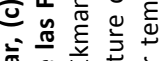

흥 현

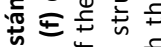

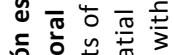

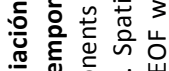

㟧

그응

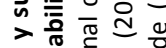

可 要

है

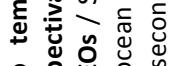

읗 울 땐동

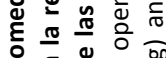

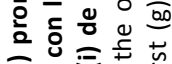

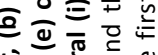

은 융

है छำ

오윻후 홍

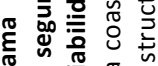

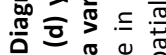

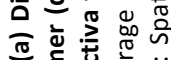

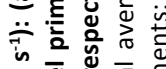

先造这

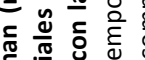

勏

웡 응

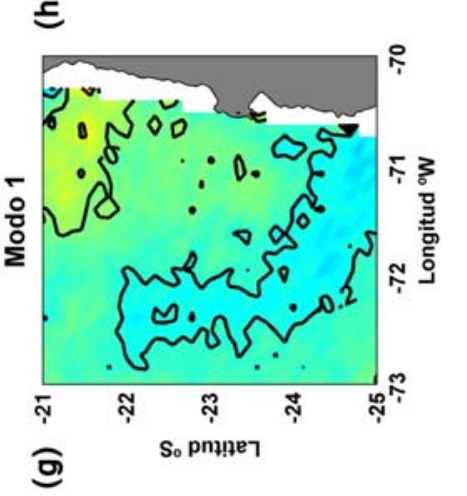

뉸

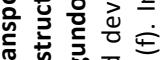

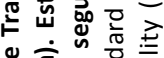

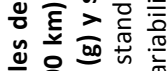

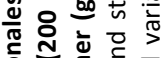
음 들

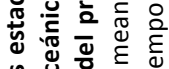
पू 它 品

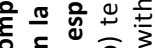
ర워 จं >

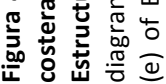




\section{Discusión}

Los resultados presentados muestran que la península de Mejillones ejerce una influencia importante en la variabilidad oceanográfica entre los $22^{\circ}$ y $24^{\circ} \mathrm{S}$, más de lo que representaría solamente un accidente topográfico. De hecho, los resultados mostraron que la península es un límite latitudinal para la distribución espacial de la clorofila. Esta singular estructura determina patrones de circulación atmosférica y oceánica locales como también procesos de retención asociados a sus bahías. La distribución de la TSM, promedio temporal en función de la latitud como también el modo 1 (FEOs), evidenciaron un ciclo anual marcado dominado por el ciclo anual de la radiación solar (Blanco et al. 2001). Estos resultados junto con las series de anomalías, utilizadas para el cálculo de las FEOs, mostraron que la amplitud de la señal anual estimada del período 2002-2010 sobrepasa ampliamente las anomalías producidas por eventos interanuales, de hecho estas anomalías intensifican o debilitan el ciclo anual de la TSM en la zona (Pizarro et al. 1994, Hormazábal et al. 2001). Otra estructura vinculada a la TSM que aparece casi permanente adyacente a la costa es una banda de aguas frías definida hacia el oeste por un frente térmico de surgencia (Hormazábal et al. 2001, Letelier et al. 2009) y que incrementó su ancho desde la península hacia el sur junto con el incremento del transporte de Ekman.

El viento favorable a la surgencia durante todo el año, reflejado en el modo 1 y en la climatología del transporte de Ekman (Fig. 4a), es responsable de la formación de esta banda de agua fría al producir el ascenso de aguas subsuperficiales en la costa (Smith 1968) por lo que, un incremento en el ancho de banda costera es consistente con un aumento de la intensidad del transporte de Ekman al sur de la península $\left(>6 \times 10^{3} \mathrm{~m}^{3} \mathrm{~s}^{-1}\right)$. El comportamiento anual de la intensidad del viento favorable a la surgencia en el norte de Chile está asociado al movimiento estacional del anticiclón del Pacifico Sur (Bakun \& Nelson 1991, Pizarro 1999). La distribución del transporte de Ekman no es heterogénea a lo largo de la costa, pero los resultados mostraron claramente como la distribución espacial y temporal cambian significativamente al norte y sur de la península. De hecho, la presencia de la península genera un quiebre en la tendencia de aumento del transporte de Ekman hacia el sur a lo largo de la costa como se evidencia al compararlo con la zona oceánica. Este quiebre asociado a un máximo en la latitud crítica $\left(22,8^{\circ} \mathrm{S}\right)$ generó un mínimo local al sur y norte de la península lo que a su vez trae como consecuencia la formación de un rotor positivo adyacente a esta estructura y un rotor negativo que favorece los flujos hacia la costa y el ecuador al norte de Mejillones. Esta distribución favorece la divergencia de las corrientes al sur de la península y la convergencia al norte tal como evidencian los resultados.

El segundo modo (FEOs) de la TSM muestra una oscilación entre la zona oceánica (noroeste) y costera (sureste), cuyo eje de oscilación es la latitud crítica asociada a la península de Mejillones, coincidente con el quiebre que muestra el perfil promedio latitudinal del transporte de Ekman (Fig. 4c). Esta oscilación espacial se invierte de primavera-verano a otoño-invierno, revelando una fluctuación semianual que conecta el Pacífico subecuatorial con la región de Antofagasta. Oscilaciones semianuales similares fueron mostradas por Shaffer et al. (1999). Este cambio de fase es coherente con el comportamiento temporal observado en el segundo modo del transporte de Ekman (Fig. 4i). Ramos (2009) mostró que este tipo de oscilación semianual, en fase opuesta con el océano subecuatorial, está relacionado con la propagación hacia el oeste de ondas Rossby semianuales forzadas por el viento.

Una característica singular asociada a la península es la formación de dos bandas de menor temperatura, asociadas a punta Angamos y punta Tetas, que limitan geográficamente la cabeza de la península (Fig. 2a). La banda norte está producida por la surgencia de punta Angamos ( $\left.23^{\circ} 01^{\prime} \mathrm{S}\right)$, que se proyecta hacia el oeste, mientras que la banda de aguas frías sur es producto de la desviación de la corriente de chorro que transporta agua de surgencia proveniente del foco de punta Coloso (234도) (Fonseca \& Farías 1987, Sobarzo \& Figueroa 2001, Reyes et al. 2007). La presencia de esta corriente de chorro a lo largo de la costa y el quiebre hacia el oeste que se produce en presencia del extremo sur de la península fue mostrada en los resultados (Fig. 5a,b) y ha sido documentada como también modelada (Escribano et al. 2004, Aguirre et al. 2011). Cabe señalar que además de un efecto topográfico como ha sido descrito, los resultados mostraron que el acoplamiento entre el viento (transporte) y la topografía refuerzan esta distribución. La desviación de la corriente de chorro también ha sido mencionada como una bifurcación, ya que parte de la corriente sería contenida dentro de las bahías de la península (Escribano \& Hidalgo 2001, Escribano et al. 2004), pero dada la resolución espacial de la información de corrientes esta no puede ser resuelta. Solamente cabe mencionar que hacia la costa, detrás de las bandas de agua fría en las puntas de la península, aparecen 

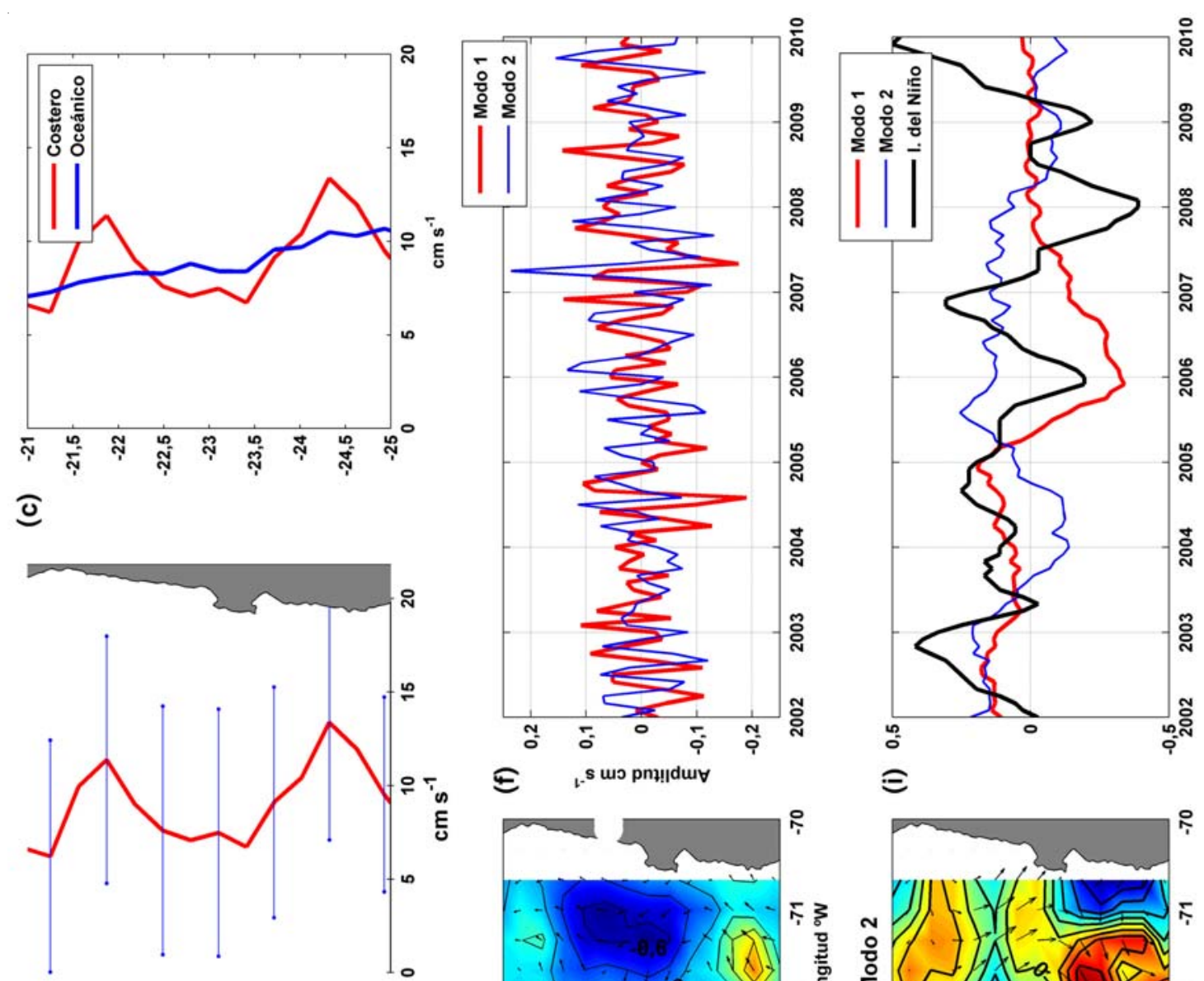

a

S. pny!ฺา
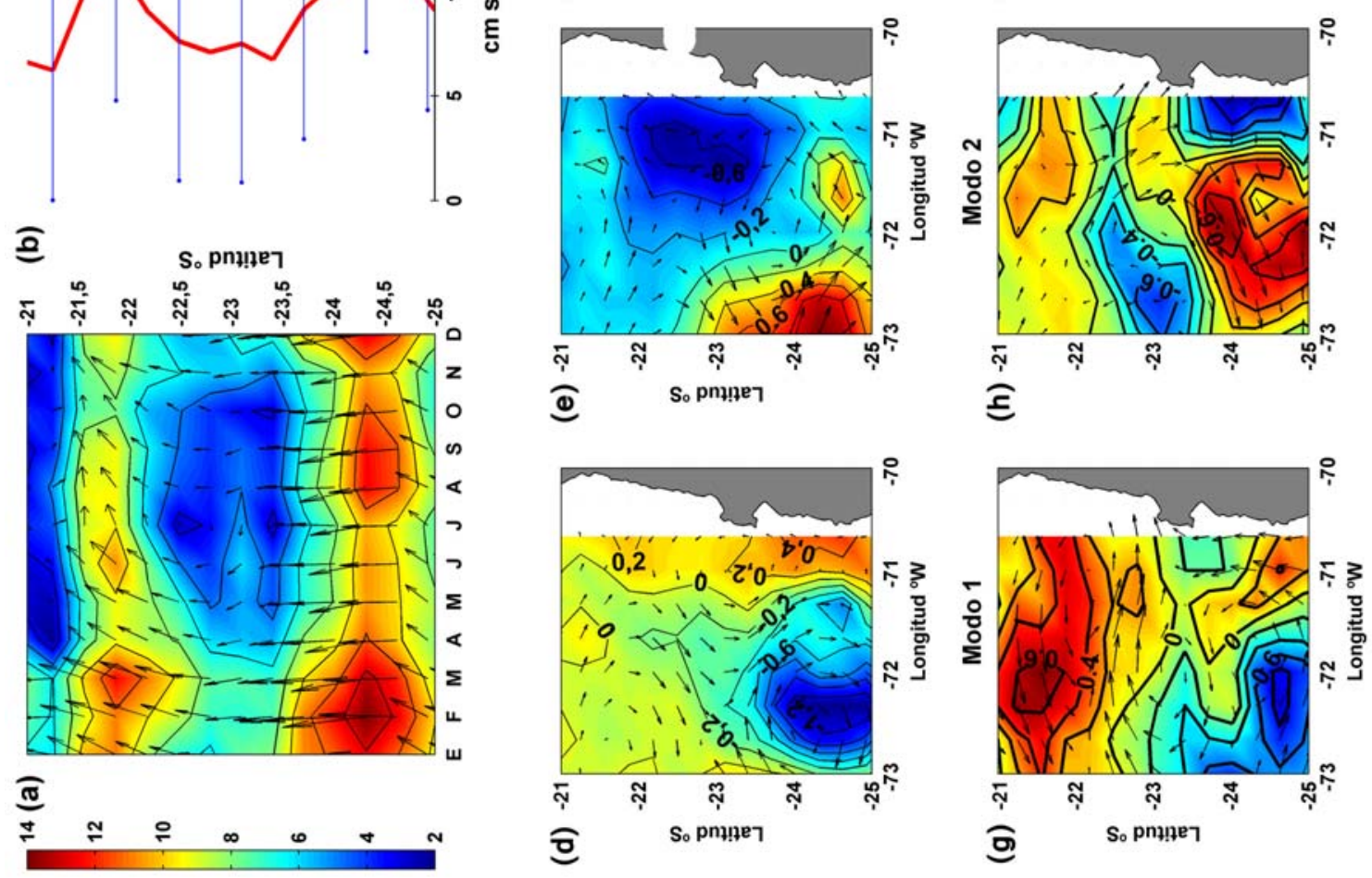

乐

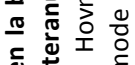

ฮ.

흔

छ

읗 흥 응 등 층

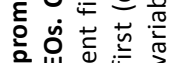

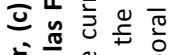

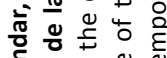

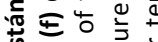

पू

它

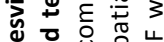

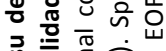

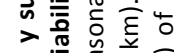

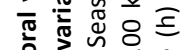

을 중

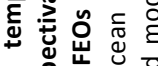

읗

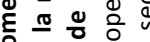

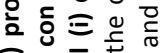

르의 뚱

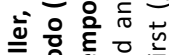

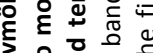

옹ㅇㅁ융 윤

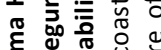

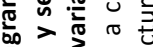

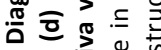

즐

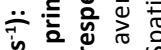

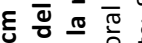

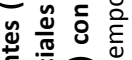

는

흔 응

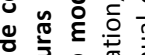

운 융

है

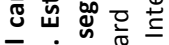

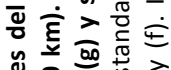

近可覀

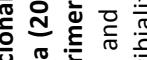

选

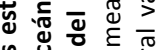

过造

它

ํㅡㄴ 응

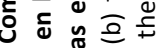

น 
anomalías positivas en la TSM $\left(+1^{\circ} \mathrm{C}\right)$ que sugieren esta bifurcación. Estas anomalías positivas aparecen en un promedio aritmético simple de las imágenes de TSM e indicarían indirectamente procesos de retención dentro de las bahías asociados a un efecto de sombra de surgencia como ha sido descrito para esta zona por Marin et al. (1993, 2003) y Escribano \& Hidalgo (2001). Un modelo numérico implementado en la zona confirma que al interior de las bahías se generan procesos de retención que producen anomalías positivas de TSM (Escribano et al. 2004).

La retención de aguas de surgencia dentro de las bahías en conjunto con la surgencia de punta Angamos y punta Coloso explican las altas concentraciones de clorofila asociadas a las bandas de agua fría que definen oceanográficamente los límites de la península de Mejillones (Fig. 2a,b y 3a,b). Cabe señalar, que desde el punto de vista de la toma de datos satelitales, la clorofila es una variable independiente (trazador biológico) de la TSM por lo que la coincidencia en los resultados respalda lo propuesto anteriormente.

La distribución espacial resultante del modo 1 de la FEOs de la clorofila (Fig. 3d) es coherente con la formación de la banda de aguas frías de surgencia (Fig. 2a) por lo que dos variables independientes muestran que esta banda es una estructura permanente al norte de la península incluyendo la bahía de Mejillones. Por otro lado, hacia el sur de bahía Moreno las concentraciones de clorofila disminuyen rápidamente, permaneciendo en promedio menores que las de la zona norte durante todo el año. Esta diferencia espacial es explicada por la combinación entre una costa abierta y el mayor transporte forzado por el viento en la zona al sur de la península (> 5 $\left.\mathrm{x} 10^{3} \mathrm{~m}^{3} \mathrm{~s}^{-1}\right)$. La mayor intensidad del transporte de Ekman es capaz de romper la resistencia del frente costero $\left(0,03^{\circ} \mathrm{C}\right.$ $\mathrm{km}^{-1}$ ), como se observa con la expansión de la banda de aguas frías en la TSM y además reduce a una estrecha banda las mayores concentración de clorofila costera (Nixon \& Thomas 2001).

El hecho de que las bahías muestren altas concentraciones de clorofila durante todo el año, en relación a las aguas adyacentes e independientes del transporte, evidencian la retención de las aguas surgentes debido al efecto topográfico (forma y orientación de las bahías), lo que no sucede en la costa abierta directamente al sur de la península. Este efecto de no-retención o pérdida debido al intenso transporte de Ekman también ocurre en la cabeza de la península lo que confirma esta conclusión.

Los resultados muestran que la península de Mejillones es un accidente topográfico singular en la costa norte de Chile que impacta en la distribución espacial de vientos y corrientes, como también refuerza la surgencia costera y los flujos que rodean la península al modificar la distribución latitudinal del transporte de Ekman o específicamente el rotor del estrés del viento. La influencia que ejerce la península sobre el océano adyacente (> 200 km de largo de costa) y la atmosfera la definen como una unidad local, pero de relevante influencia física y biológica dentro de una zona biogeográfica de transición cuyo limite parece estar en los $30^{\circ} \mathrm{S}$ (Camus 2001), pero donde la latitud crítica encontrada entrega un nuevo factor de análisis a futuro. Los resultados mostraron que al norte de la península las variables presentan una señal anual de amplitud más débil en relación con el sur de la península, donde la banda de aguas frías es más ancha, los frentes térmicos más débiles y la banda de altas concentraciones de clorofila es más angosta moduladas por una mayor transporte de Ekman (> 5,5 x $10^{3} \mathrm{~m}^{3} \mathrm{~s}^{-1}$ ) sugieren que la península puede estar marcando un límite oceanográfico y atmosférico más significativo que el descrito en los $30^{\circ} \mathrm{S}$.

El norte de Chile se encuentra en una zona de transición dominada por patrones regionales modificados localmente por la presencia de la península de Mejillones. Esta estructura topográfica singular favorece la producción biológica en términos de la concentración de clorofila gracias al efecto de retención y sombra de surgencia producido por la forma y orientación de sus bahías. La clorofila resultante de la interacción de la surgencia de punta Angamos y punta Coloso con la península está asociada a la presencia de dos bandas zonales donde prevalecen aguas más frías que las adyacentes durante todo el año y marcan el límite norte y sur de la cabeza de la península. Esta estructura bloquea el desplazamiento hacia el norte de la corriente de chorro, la cual se proyecta hacia el oeste variando estacionalmente de intensidad y llegando a alejarse más de $100 \mathrm{~km}$ de la costa para después retornar al norte de la bahía de Mejillones. Además, de las condiciones locales que genera la presencia de península y sus bahías, la distribución costera y oceánica mostraron la presencia de una latitud crítica a $22,8^{\circ} \mathrm{S}$ donde se genera un quiebre latitudinal que interrumpe el decaimiento de la TSM, la clorofila y el incremento del transporte de Ekman. La interacción de los vientos con la topografía refuerza la circulación anticiclónica de los vientos y las corrientes como también la surgencia costera. 
Esto induce a la posible formación de una frontera biooceanográfica no mencionada anteriormente.

\section{Agradecimientos}

Agradecemos el apoyo al programa de postdoctorado de la Dirección de Investigación de la Pontificia Universidad Católica de Valparaíso y al proyecto 064307 3/R-2006 de la Dirección de Investigación de la Universidad del BíoBío.

\section{LITERATURA CITADA}

Aguirre C, O Pizarro, PTP Strub, RD Garreaud \& J Barth. 2011. Seasonal dynamics of the near-surface alongshore flow off central Chile. Journal of Geophysical Research 117 (C01006): 17 pp. <doi: 10.1029/2011JC007379>

Bakun A. 2006. Fronts and eddies as key structures in the habitat of marine fish larvae: opportunity, adaptive response and competitive advantage. Scientia Marina 70(S2): 105122.

Bakun A \& CS Nelson. 1991. The seasonal cycle of windstress curl in subtropical eastern boundary current regions. Journal of Physical Oceanography 21(12): 1815-1834.

Barnett TP. 1981. Statistical relations between ocean/ atmosphere fluctuations in the Tropical Pacific. Journal of Physical Oceanography 11(8): 1043-1058.

Barnett TP \& WC Patzert. 1980. Scales of thermal variability in the tropical Pacific. Journal of Geophysical Research 10: 529-540.

Blanco JL, M Carr, A Thomas \& P Strub. 2002. Hydrographic conditions off northern chile during the 1996 La Niña and 1997-1998 El Niño events. Journal of Geophysical Research 107(C3): 19 pp. <doi:10.1029/2001JC001002>.

Blanco JL, A Thomas, M Carr \& P Strub. 2001. Seasonal climatology of hydrographic conditons in the upwelling region off northern Chile. Journal of Geophysical Research 106(C6): 11451-11467.

Bjornsson H \& SA Venegas. 1997. A manual for EOF and SVD. Analyses of climate data, 52 pp. Department of Atmospheric and Oceanic Sciences, and Center for Climate and Global Change Research, McGill University <http:// www.geog.mcgill.ca/gec3/wp-content/uploads/2009/03/ Report-no.-1997-1.pdf>

Camus. P. 2001. Biogeografía marina de Chile continental. Revista Chilena de Historia Natural 74: 587-617.

Correa-Ramírez M, S Hormazábal \& G Yuras. 2007. Mesoscale eddies and high chlorophyll concentrations off central Chile $\left(29^{\circ}-39^{\circ} \mathrm{S}\right)$. Geophysical Research Letters 34 (L12604): <doi:10.1029/2007GL029541>.

Croissant Y \& G Millo. 2008. Panel data econometrics in R. The plm package. Journal of Statistical Software 27(2): 1-43.
Escribano R \& P Hidalgo. 2001. Circulación inducida por el viento en Bahía de Antofagasta, norte de Chile (23ㅇ). Revista de Biología Marina y Oceanografía 36(1): 43-60.

Escribano R, S Rosales \& JL Blanco. 2004. Understanding upwelling circulation off Antofagasta (northern Chile): A three-dimensional numerical-modeling approach. Continental Shelf Research 24: 37-53.

Evenson A \& G Veronis. 1975. Continuous representation of wind stress and wind stress curl over World ocean. Journal of Marine Research 33(suppl.): 131-144.

Fonseca T \& M Farías. 1987. Estudio del proceso de surgencia en la costa chilena utilizando percepción remota. Investigaciones Pesqueras 34: 33-46.

Grunfield Y. 1958. The determinants of corporate investment. Ph. D thesis, University of Chicago, 175 pp.

Hellerman S \& M Rosensteinm. 1983. Normal monthly wind stress over the world ocean with error estimates. Journal of Physical Oceanography 13: 1093-1104.

Hormazábal S, G Shaffer, J Letelier \& O Ulloa. 2001. Local and remote forcing of the sea temperature in the coastal upwelling system off Chile. Journal of Geophysical Research 106(C8): 16657-16671.

Kelly KA. 1985. The Influence of winds and topography on the sea surface temperature patterns over the northern California slope. Journal of Geophysical Research 90: 11783-11798.

Letelier J, O Pizarro \& S Nuñez. 2009. Seasonal variability of coastal upwelling and the upwelling front off central Chile. Journal of Geophysical Research 114 (C12009): 16 pp. doi:10.1029/2008JC005171.

Marin V, L Delgado \& R Escribano. 2003. Upwelling shadows at Mejillones Bay (northern Chilean coast): a remote sensing in situ analysis. Investigaciones Marinas 31(2): 47-55.

Marin V, L Rodriguez, L Vallejo, J Fuenteseca \& E Oyarce. 1993. Efectos de la surgencia costera sobre la productividad primaria primaveral de Bahía Mejillones del Sur (Antofagasta, Chile). Revista Chilena de Historia Natural 66: 479-491.

Nixon S \& A Thomas. 2001. On the size of the Peru upwelling ecosystem. Deep Sea Research I 48: 2521-2528.

Pizarro O. 1999. Low frequency fluctuations in the eastern boundary current offsouth america: Remote and local forcing. Tesis Ph. D. Earth Sciences Centre, Göteborg, 36 pp.

Pizarro O, S Hormazábal, A González \& E Yáñez. 1994. Variabilidad del viento, nivel del mar y temperatura en la costa norte de Chile. Investigaciones Marinas 22:85-101.

Pizarro O, G Shaffer, B Dewitte \& M Ramos. 2002. Dynamics of seasonal and interannual variability of the Peru-Chile Undercurrent. Geophysical Research Letters 29(12): 1581-1584.

Pond S \& GL Pickard. 1983. Introductory dynamical oceanography, 329 pp. Butterworth Heinemann, Oxford. 
Ramos M. 2009. Fluctuaciones de baja frecuencia en el Pacífico sudoriental y su relación con ondas de Rossby: Comparación entre observaciones y teoría. Tesis de Oceanografía, Universidad de Concepción, Concepción, 142 pp.

Reyes H. 2004. Variación espacio-temporal de las masas de agua Subtropical, Subantártica y Ecuatorial Subsuperficial en la zona norte de Chile ( $18^{\circ} 15^{\prime}$ S $-24^{\circ} 00^{\prime}$ S $)$ en el período 1980-2001. Tesis de Oceanografía, Pontificia Universidad Católica de Valparaíso, Valparaíso, 114 pp.

Reyes H, J Letelier \& M Pizarro. 2007. Distribucion espacial de variables oceanográficas en: Monitoreo de las condiciones bio-oceanográficas entre la I y IV regiones, año 2007. FIP 2007-11: 1-255. Fondo de Investigación Pesquera, Valparaíso. < http://www.fip.cl/proyectos/2007/200711.htm.>

Reyes H, J Letelier, M Pizarro \& M Braun. 2009. Condición oceanográfica en: evaluación de stock desovante de la anchoveta en la I y II Regiones, año 2008. FIP 2008-01: 1314, Instituto de Fomento Pesquero, Valparaiso. <http:// www.fip.cl/proyectos/2008/2008-01.htm>

Rojas R \& N Silva. 1996. Atlas oceanográfico de Chile (18²1’S-5000’S). Volumen I: 1-234. Servicio Hidrográfico y Oceanográfico, Armada de Chile, Valparaíso.

Rutllant J, H Fuenzalida \& P Aceituno. 2003. Climate dynamics along the arid Northern coast of Chile: The 19971998 Dinámica del clima de la Región de Antofagasta (DICLIMA) experiment. Journal of Geophysical Research, Atmospheres 108(D17): 4358.

Shaffer G, O Pizarro, L Djurfeldt \& S Salinas. 1997. Circulation and low-frequency variability near the Chilean coast: Remotely forced fluctuations during the 1991-92 El Niño. Journal of Physical Oceanography 27: 217-235.

Shaffer G, S Hormazábal, O Pizarro \& S Salinas. 1999. Seasonal and interannual variability of currents and temperature off central Chile. Journal of Geophysical Research 104(C12): 29951-29961.
Sievers H \& N Silva. 1982. Masas de agua y circulación geostrofica frente a la costa de Chile entre las latitudes $18^{\circ} \mathrm{S}-33^{\circ} \mathrm{S}$ (Operación Oceanográfica MARCHILE VII). Ciencia y Tecnología del Mar 6: 61-99.

Silva N. 1983. Masas de agua y circulación de la región norte de Chile. Latitudes $18^{\circ} \mathrm{S}-32^{\circ} \mathrm{S}$. (Operación Oceanográfica MARCHILE XI - ERFEN II). Ciencia y Tecnología del Mar 7: 47-84.

Smith R. 1968. Upwelling. Oceanography and Marine Biology: An Annual Review: 6: 11-46.

Sobarzo M \& D Figueroa. 2001. The physical structure of a cold filament in a Chilean upwelling zone (Península de Mejillones, Chile, $23^{\circ}$ S). Deep Sea Research I 48: 26992726.

Strub P, J Mesías, V Montecino, J Rutlland \& S Salinas. 1998. Coastal ocean circulation off western south America. Chapter 10. In: Robinson AR \& KH Brink (eds). The sea: The global coastal ocean, regional studies and synthesis, pp. 273-313. John Wiley and Sons, New York.

Thiel M, EC Macaya, E Acuña, WE Arntz, H Bastias, K Brokordt, PA Camus, JC Castilla, LR Castro, M Cortés, CP Dumont, R Escribano, M Fernandez, JA Gajardo, CF Gaymer, I Gomez, AE González, HE González, PA Haye, JE Illanes, JL Iriarte, DA Lancellotti, G LunaJorquera, C Luxoro, PH Manriquez, V Marín, P Muñoz, SA Navarrete, E Perez, E Poulin, J Sellanes, HH Sepúlveda, W Stotz, F Tala, A Thomas, CA Vargas, JA Vasquez \& A Vega. 2007. The Humboldt current system of northern and central Chile - Oceanographic processes, ecological interactions and socioeconomic feedback. Oceanography and Marine Biology: An Annual Review 45: 195-344.

Venegas S. 2001. Statistical Method for signal detection in climate, 96 pp. Danish Center for Earth System Science, (DCESS), Copenhagen.

Yuras G, O Ulloa \& S Hormazabal. 2005. On the annual cycle of coastal and open ocean satellite chlorophyll off Chile (18 $\left.-40^{\circ} \mathrm{S}\right)$. Geophysical Research Letters 32: L23604.

Recibido el 9 de enero de 2012 y aceptado el 16 de noviembre de 2012

Editor Asociado: Mauricio Landaeta D. 